\title{
Hemoglobin Decreased
}

National Cancer Institute

\section{Source}

National Cancer Institute. Hemoglobin Decreased. NCI Thesaurus. Code C80085.

A laboratory test result demonstrating decreased levels of hemog lobin in a biological specimen. 